2019-04-25

\title{
Transcription, Analysis, Interpretation and Translation in cross-cultural research
}

\section{Arunasalam, N::0000-0003-2040-8321}

http://hdl.handle.net/10026.1/12555

\subsection{8/nr.2019.e1605}

Nurse Researcher

RCN Publishing

All content in PEARL is protected by copyright law. Author manuscripts are made available in accordance with publisher policies. Please cite only the published version using the details provided on the item record or document. In the absence of an open licence (e.g. Creative Commons), permissions for further reuse of content should be sought from the publisher or author. 


\section{Reflection: Transcription, Analysis, Interpretation and Translation}

Background This paper reports on the process of data transcription, analysis, interpretation and translation in a study conducted with Malaysian nurses who studied on one Australian and two UK Transnational Higher Education postregistration top-up nursing degree programmes. An interpretive paradigm and hermeneutic phenomenology and the ethnographic principle of cultural interpretation designs was used. Semi-structured interviews were undertaken in English and Bahasa Malaysia (Malaysian language).

Interview recordings were transcribed and data was analysed using thematic analysis to identify sub-themes and themes. Personal and analytical notes recorded were used for the interpretation, discussion of the findings and to provide an audit trail justifying decision making throughout the research process. Interview extracts were used for the presentation of the findings and, where the data was in both Bahasa Malaysia and English, only the Bahasa Malaysia part of the conversation was translated.

Aim To examine the process of transcription, analysis, interpretation and translation of data.

Discussion To undertake this process in international cross-cultural research where dual languages are used, the researcher would need to consider and address certain factors. This is to allow the relationship between the extracts, research question and literature to illuminate views that are faithful to participants' experiences. It also assists novice researchers and reviewers of scientific articles.

Conclusion Thematic analysis enabled patterns, categories and themes to be revealed.

Implications for practice This reflective paper adds to the discussion on the process of transcription to the presentation of the findings in a study that used dual languages to collect the data.

Keywords Transcription, data analysis, interpretation, translation, hermeneutic analysis, hermeneutic phenomenological process.

\section{Introduction}

In Malaysia, the Malaysian Nursing Board (MNB) allowed private colleges linked to private hospitals, private higher education institutions (HEls) and public universities to collaborate with western Transnational Higher Education (TNHE) institutions for the provision of part-time post-registration top-up degree programmes (Arunasalam, 2013; 2016). The focus of TNHE providers is to raise their profiles and influence in the Asian region, and the MNB embraced TNHE programmes, as there is limited provision of these types of degrees (Ziguras, 2008). 'Flying faculty' academics 'fly in' to Malaysia from the provider HEls for one to two weeks to deliver teaching. On completion of the teaching, they 'fly out' to their country. 
As nursing is a practice-based profession, the rationale to undertake this study was to identify whether the Malaysian nurses were able to apply the nursing knowledge taught in the TNHE classroom in the provision of patient care in the multicultural, multiracial and multilingual healthcare system (Arunasalam, 2013). The internationalisation of higher education has led to the need for international crosscultural studies to improve understanding of cross-cultural phenomena.

The interpretive paradigm was chosen as the study aimed to examine Malaysian nurses' views of the connection between TNHE theory and Malaysian practice. A hermeneutic phenomenological approach (van Manen, 2014) allowed the nurses to reflect on their experiences. These nurses used both English and Bahasa Malaysia or dual languages to relate their views. This is because English is a second or third language in Malaysia and the pilot study interviews identified that nurses had difficulty expressing themselves in English only. In addition, the hermeneutic phenomenological design allowed the researcher to be part of the study and make decisions throughout the research process (van Manen, 2014). The ethnographic principle of cultural interpretation (Geertz, 1973) also informed this study, as it enabled both an emic and etic outlook to be utilised to reveal meanings for the reader of the text.

In this paper, the transcription, analysis, interpretation and translation phase of the research involving eighteen Malaysian nurses (recruited via convenience and snowball sampling methods) who studied on one Australian and two UK TNHE postregistration top-up degree programmes will be reported (Arunasalam, 2013; 2016). The rationale for choosing the methods, and useful strategies that may be adopted with participants in Asian countries, have been outlined.

\section{Transcription of interviews}

Transcription, the first stage in data analysis, can be undertaken by recording every utterance and word (naturalism) or by removing elements of speech like pauses and non-verbal communication (denaturalism) (Oliver, Serovich \& Mason, 2005). For this research, the transcribed data focused only on what was said in relation to the study as it aimed to answer the research question. Thus, pauses, jokes and other aspects of the interaction between the researcher and nurses were omitted. 
The digitally recorded interviews were self-transcribed by the researcher for this research. Perakyla (2005) supports this approach as repeated listening of the data offers a deeper form of connection to the data, although Bailey (2008) argues that this will cause the researcher to make judgments and shape the meaning of the words.

In addition, Polit and Beck (2010) advised that each participant's transcript be examined against the audio recording to confirm the conversation. Silverman (2016) agreed but stressed, like Kvale (1996), that it is also important to return the transcripts to the participants to read. He emphasised that it confirms accuracy and ensures rigour by verifying the validity and credibility of the data. The dual language transcripts from this study were emailed to the nurses. Only ten out of the eighteen nurses responded but all ten confirmed the correctness of the record and none asked to add, amend or remove any details.

\section{Data analysis}

In this study, thematic analysis was used. The initial stage involved quiet time and a reflexive stance where each interview data is analysed individually using van Manen's (2014) detailed (what each sentence or group of sentences reveal about the phenomenon), selective (what is essential or revealed in the text), and holistic (what phrase captures the meaning of the text) reading approaches. All the scripts were annotated by hand, as the transcribed data were in dual languages with different grammar and sentence construction. A column was inserted on the lefthand side of the interview transcripts to allow codes given to participants to be included. Then, a column was inserted on the right-hand side margin of the transcripts to record ideas, thoughts, personal and analytical reflection notes for each semi-structured interview transcript.

The aim was to select and highlight words and sentences that had significance to the research question. For each of the eighteen participants' transcripts, a word or phrase was colour coded in line to a grouping in the right-hand side of the transcript. It formed the early categories. Then, as van Manen (2014) suggested, these were reviewed, questioned and considered against all eighteen interviewees' data. This was to identify shared and conflicting views of their experiences. Phrases or sentences were then 
removed from each of the eighteen transcripts to give an overall impression of participants' experiences. It allowed statements to be grouped into similar categories and tabulated into sections in a series of tables in Microsoft Word documents. It allowed the views of nurses to be examined as a whole.

Only when ideas started to form did the researcher return to the data that had been reduced into categories that were similar or different. This introduced a freshness to the approach and enabled the focus to shift from identifying phrases to identifying subthemes and themes. Heidegger (1962: 104) reminds us "we never come to thoughts, they come to us". This method involved extracting meaning from the interview data by filtering it through the nurses' view, instead of the researcher's, to establish the background of the study (Patton, 2002). A coding sheet was developed for numerical recording of recurring concepts that emerged so the frequency of these patterns could be used to make contrasts.

Through the process of writing and rewriting, the feelings, thoughts and attitudes of the nurses became apparent. These themes are used as a framework to create a text that outlines the meanings of the phenomenon from the data. Further, constant questioning and reflection led to a deeper insight into their experience.

It was easy to immerse in the experiences of the nurses and become distracted from the research question. To avoid being side-tracked, two types of field notes recording were undertaken: one personal (detailed information of nurses, reflective notes on methodological and interview experience including potential influence on data collection) and one analytical (insights and emerging ideas). It improved focus on the research question, informed the thoughts and decisions of the researcher, and assisted in the analysis and interpretation of the findings.

\section{Interpretation}

The personal and analytical recordings undertaken were used in the process of interpretation and discussion of the participants' data. These notes were useful as a reminder of the thought processes for decision making throughout the research. Koch (1994) stressed that an audit trail explaining and justifying decision making of the research process is important to strengthen the trustworthiness of the research. 
It requires personal and analytical typed accounts recorded in a journal with thoughts, memories, views and experiences. It would assist reflection during the interpretation of the interview data (van Manen, 2014).

Interpretation is defined by Patton (2002: 480) as

"... going beyond the descriptive data. Interpretation means attaching significance to what was found, making sense of findings, offering explanations, drawing conclusions, extrapolating lessons, making inferences, considering meanings, and otherwise imposing order on an unruly but surely patterned world."

Van Manen's process focuses on the concept of the hermeneutic circle as, during interpretation of the interview data, the researcher moves in and out of an imaginary hermeneutic circle, connecting with the parts, then the whole, and then the parts once more, each time taking increasing understanding with them. The hermeneutic circle refers to the idea that one's understanding of a phenomenon as a whole is determined with reference to the individual parts, and one's understanding of each individual part by reference to the whole (van Manen,2014). It involves the back and forth movement of the researcher and the text to analyse and interpret participants' experiences.

Reflecting on the essential themes which characterise the phenomenon, the emphasis is on the analysis process itself, by reflecting on the themes identified from the interviews and endeavouring to capture the essential meaning or essence of the lived experience in question. Van Manen (1997) points out that there is "a distinction between appearance and essence" (p. 31), that which we tend to see as everyday and that which is obscure, and phenomenological research allows this to be brought into focus. The aim is to make visible feelings, thoughts and attitudes of participants.

The shift from data analysis to interpretation means the focus is on the views of the nurses. Personal insights, knowledge and literature were used to examine the data to select common phrases, sub-themes and themes. This enables the researcher to identify aspects that are of value from the data that has been analysed and to interpret, through reflection, an explicit description of nurses' views for the reader to understand. 
It was also important to continually read, contemplate, reflect, reveal and write on the phrases, sub-themes and themes identified from the transcription. The hermeneutic circle framework (van Manen, 1990) allows the researcher to move backwards and forwards between the experiences of individual interviews and all interviews to look for patterns, repeated or shared experiences of the individuals. It is pertinent to move within the hermeneutic circle in an attempt to make sense of individual nurses and all eighteen nurses' experiences.

During this repeated stages of interpretation, an unfolding and infolding occurs which enables patterns to emerge from the data to produce a description. In keeping nurses at the centre of data interpretation, their experiences could be unravelled to make sense of the meaning for the reader. The use of data excerpts to illustrate the themes and the comparison of others' interpretations adds credibility to this research. Cocreating the research text would ensure the researcher would not dominate the interpretations, or alter perceptions of the data collected, or the choices around including or excluding the nurses' and the researcher's views to provide both an emic and etic perspective for the reader. The presentation of the findings also uncovers the researcher's values and views as they interpret and reveal participants' reality. The researcher uses their reflexive views to connect with the shared experiences of the interviewees in order to make sense of the meaning about participants and society. This is because the data is interpreted either through nurses' views or the cultural beliefs of Malaysian society or through the researcher's views.

\section{Translation}

The interview data was collected, transcribed, analysed and interpreted in the original languages of the interviews, Bahasa Malaysia and English. Birbili (2000) stresses that data collection in one language and presentation of the findings in another requires the researcher to undertake translation-related decisions, because the text cannot be translated literally due to idiomatic words and phrases (Kamler \& Threadgold, 2003). Thus, the translator needs to have knowledge and understanding of the history and culture of the society. This will enable them to translate words or phrases to ensure that the meaning does not get "lost - not in, but by - translation" (Birbili, 2000;17). 
Honig (1997: cited in Birbili, 2000) states that a word-by-word translation would be an accurate representation of participants' views through their language and allows readers to understand the foreign outlook. But, Birbili (2000) argues that the readability of the text would be reduced as it would be difficult to understand their views.

Temple and Young (2004: 167) emphasise that,

"translation itself has power to reinforce cross-cultural relationships but that power tends to rest in how translation is executed and integrated into research design and not just in the act of translation per se".

In this research, the interview extracts chosen for the presentation of the findings were shown in italics and were left in their authentic state, or as close to their original state for quotations that needed translation into English. Hence, where both English and Bahasa Malaysia were used in data collection, only the Bahasa Malaysia part of the interaction was translated. Thus, despite the fluency of the interviewees during data collection, some quotations used appeared disjointed.

\section{Conclusion}

In conclusion, this article outlined the approaches that may be considered in transcribing, data analysis, interpretation and translation of dual language data collection with Asian participants. The transcription of the data was focused on what was said in relation to this study. Data was analysed using thematic analysis with the interpretation directed towards the nurses' experiences. Translation of the chosen extracts aimed to provide an accurate representation of nurses' views.

\section{Implications for research and practice}

In an increasingly globalized economy, the impact of cross-cultural exchanges have grown to show us similarities and differences. This reflective paper adds to the discussion on the process of transcription, analysis, interpretation and translation in a research where dual languages were used. It provides factors that assist novice researchers and reviewers of scientific articles to consider and address to ensure the nurses' views are faithful to their experiences. 


\section{References}

Abdullah A (1992) The Influence of Ethnic Values on Managerial Practices in Malaysia. Malaysian Management Review. 27,1, 3-18.

Abdullah A \& Koh SL (2009) Culture Matters in Malaysia. Pearson Prentice Hall, Kuala Lumpur, Malaysia.

Agar M (2000) The Professional Stranger: An informal introduction to ethnography. Academic Press, New York.

Arunasalam ND (2016) Malaysian Nurses Motivation to Study on Transnational Higher Education Programmes. Malaysian Journal of Nursing. 7, 2, 34-41.

Arunasalam ND (2013) A defining moment: Malaysian nurses' perspectives of transnational higher education (Doctoral dissertation, University of Hertfordshire).

Babbie E (2011) The Basics of Social Research. Wadsworth Publishing. Belmont, California.

Birbili M (2000). Translating from one language to another. Social Research Update 31, University of Surrey, http://sru.soc.surrey.ac.uk/SRU31.html

Baguley M, Yvonne S, Martin F \& Kerby, C (2015) Meanings and Motivation in Education Research. Routledge. Oxon, UK.

Bergold J \& Thomas S (2012) Participatory Research Methods: A Methodological Approach in Motion. Qualitative Social Research. 13,1,30.

Bradshaw M \& Stratford E (2010) Qualitative research design and rigour. In lain Hay (edn). Qualitative Research Methods in Human Geography. Oxford University Press. Oxford, UK. 37-49

Bourke B (2014) Positionality: Reflecting on the Research Process. The Qualitative Report. 19.

Cohen L, Manion L \& Morrison K (2011) Research Methods in Education. 7th edn. Routledge. London.

Creswell JW (2013) Qualitative inquiry and research design: Choosing among five approaches. $4^{\text {th }}$ edition. SAGE. Thousand Oaks, California

Denzin NK \& Lincoln YS (2011) Handbook of qualitative research. 2nd edition. SAGE. Thousand Oaks, California.

Doody, Owen \& Noonan, Maria (2013). Preparing and conducting interviews to collect data. Nurse Researcher, 20, 5, 28-32.

Etherington K (2004) Becoming a Reflexive Researcher. Jessica Kingsley. London. 
Geertz C (1973) The Interpretation of Cultures: Selected Essays. Basic Books. New York.

Goffman E (1959) The Presentation of Self in Everyday Life. Doubleday. Garden City, New York.

Hayfield N \& Huxley C (2015) Insider and outsider perspectives: Reflections on researcher identities in research with lesbian and bisexual women. Qualitative Research in Psychology. 12, 2, 91-106.

Husserl E (1964/1929) The Paris Lectures. Martinus Nijhoff. The Hague. Iphofen R (2011) Ethical Decision Making in Social Research: A Practical Guide Palgrave Macmillan. Hampshire, UK

Kamler B \& Threadgold T (2003) 'Translating Difference: questions of representation in cross-cultural research encounters' Journal of Intercultural StudiesVol.24, No. 2, 137-151

King V (2008) Malaysia - Culture Smart. The Essential Guide to Customs \& Culture. K.U.P.E.R.A.R.D.

Kvale S \& Brinkmann S (2009) Interviews: learning the craft of qualitative research interviewing. (2nd edition). SAGE. Thousand Oaks, California.

Maanenn J (2011) Tales of the Field: On Writing Ethnography. 2nd edn. Chicago. Merleau-Ponty M (1962) The Phenomenology of Perception. Routledge \& Kegan Paul. London.

Richardson L (2013) Writing: A Method of Inquiry. Autoethnography. SAGE. California.

Schutz A (1964) Collected papers II: studies in social theory. A. Brodersen (ed.) Martinus Nijhoff. The Hague.

Schutz A (1976) The Stranger. In Race and Ethnic Relations. Edited by Bowker G \& Carrier J. Hutchison. London.

Savin Baden M (2004) Achieving reflexivity: moving researchers from analysis to interpretation in collaborative enquiry. Journal of Social Work Practice.18, 3, 365-378.

Savin-Baden M \& Major C (2013) Personal stance, positionality and reflexivity in Qualitative Research. The essential guide to theory and practice. Routledge. London.

Silverman D (2016) Qualitative Research. $4^{\text {th }}$ Edition. SAGE Publications Ltd. London.

Temple B and A Young (2004). Qualitative Research and Translation Dilemmas. Qualitative Research 4(2): 161-178. 
Umberson D \& Montez JK (2010) Social relationships and health: a flashpoint for health policy. Journal Health Social Behaviour. 51 Supplement: S54-66.

Van Manen M (2014) Phenomenology of Practice. Meaning-Giving Methods in Phenomenological research and writing. Left Coast Press, Inc. Walnut Creek, California.

Wolcott F H (2008) Ethnography: A Way of Seeing. 2nd edn. Altamira Press, USA. 